\title{
Importance of footing-soil separation on dynamic stiffness of piled embedded footings*
}

\author{
L.A. Padrón ${ }^{1}$, G. E. Mylonakis ${ }^{2}$, D.E. Beskos ${ }^{2}$ \\ 1. University Institute SIANI, Universidad de Las Palmas de Gran Canaria, Campus \\ Universitario de Tafira, 35017 Las Palmas de Gran Canaria, Spain \\ 2. Department of Civil Engineering, University of Patras, GR-26500, Patras, Greece
}

\begin{abstract}
Different phenomena such as soil consolidation, erosion, and scour beneath an embedded footing supported on piles may lead to loss of contact between soil and the pile cap underside. The importance of this separation on the dynamic stiffness and damping of the foundation is assessed in this work. To this end, a numerical parametric analysis in the frequency domain is performed using a rigorous threedimensional elastodynamic BEM-FEM coupling method. Dimensionless plots relating dynamic stiffness functions computed with and without separation effects are presented for different pile-soil configurations. Vertical, horizontal and rocking modes of oscillation are analyzed for a wide range of dimensionless frequencies. It is shown that the importance of separation is negligible for frequencies below those for which dynamic pile group effects start to become apparent. Redistribution of stiffness contributions between piles and footing is also addressed.
\end{abstract}

Keywords: Pile group, Embedded footing, Piled footing, Soil-structure interaction, Dynamic stiffness, Soil consolidation, Boundary element method

\section{Introduction}

When soil under a footing consolidates, significant settlement may be generated depending on the compressibility and thickness of the soil material. When this phenomenon is expected to take place, the magnitude of settlement can be limited by the addition of piles under the footing. In this case, foundation stiffness is increased, but the contact between soil and pile cap underside may be lost and a series of gaps form under the footing (Fig. 1). Analogous effects may take place due to erosion or scour in the soil.

The importance of the presence of this separation on the dynamic behaviour of a piled embedded footing has not been assessed to date. A related topic is the influence of a ground-contacting cap on the performance of a pile foundation $[1,2,3]$. A common assumption is that the cap is separated from the ground, as its contribution to stiffness is often negligible. This assumption has been checked [2, 3], but, to the extent of the Authors' knowledge, it has never been verified in the case of pile groups under embedded footings. It is worth mentioning that the behaviour of pile rafts (where separation effects can also take place) is a different topic in which research findings have been reported $[4,5]$.

\footnotetext{
*This is the peer-reviewed version of the following article: Padrón, Mylonakis, Beskos, Importance of footing-soil separation on dynamic stiffness of piled embedded footings, Int $\mathrm{J}$ Numerical and Analytical Methods in Geomechanics 2009; 33:1439-1448, which has been published in final form at http://onlinelibrary.wiley.com/doi/10.1002/eqe.2330/full. This article may be used for non-commercial purposes in accordance with Wiley Terms and Conditions for Self-Archiving.
} 
In this paper, the influence of footing-soil separation at the base of a rigid piled embedded footing on the dynamic stiffness and damping is assessed. To this end, a numerical parametric analysis in the frequency domain is performed for different pile-soil stiffness ratios, embedment ratios and pile-to-pile separations, making use of a rigorous linear boundary element - finite element coupling formulation [6]. It is shown that the influence is negligible for frequencies below those for which dynamic pile group effects start to become apparent. Redistribution of stiffness between piles and footing is also discussed.

\section{Problem parameters}

The geometry of the model is depicted in Fig. 1, where $B$ and $D$ are foundation halfwidth and depth of embedment, $L$ and $d$ are length and sectional diameter of piles, and $s$ is the center-to-center spacing between adjacent piles. In this study, $B / \mathrm{s}=n / 2$ where $n=$ number of piles per side in square configuration. The dimensionless parameters sets considered are: $s / d=2$ and $5, D / B=1$ and 2, pile-soil stiffness contrast $E_{\mathrm{p}} / E_{\mathrm{s}}=1000$ and $100, n=2$ and $3-$ leading to $\mathrm{B} / \mathrm{s}=1$ and 1.5 , dimensionless frequency $a_{\mathrm{o}}=0$ to 1 in steps of $0.05-$ a total of 336 parameter combinations. The dimensionless frequency is defined as $a_{\mathrm{o}}=\omega \mathrm{d} / \mathrm{c}_{\mathrm{s}}$, where $\omega$ is the circular frequency of excitation and $c_{s}$ is the shear wave propagation velocity in the soil. The rest of properties, having generally second-order influence on dynamic response, are: mass density contrast between soil and pile $\rho_{\mathrm{s}} / \rho_{\mathrm{p}}=0.7$, pile slenderness ratio $L / d=15$, soil damping coefficient $\xi=0.05$ and soil Poisson's ratio $v_{\mathrm{s}}=0.4$. Note that the total number of dimensionless ratios describing the response is ten $(L / d, s / d, B / s, D / B$, $\left.E_{\mathrm{p}} / E_{\mathrm{s}}, \rho_{\mathrm{s}} / \rho_{\mathrm{p}}, a_{\mathrm{o}}, n, \xi, v_{\mathrm{s}}\right)$, being equal to the difference between thirteen dimensional and dimensionless quantities $\left(L, s, d, B, D, E_{\mathrm{p}}, E_{\mathrm{s}}, \rho_{\mathrm{s}}, \rho_{\mathrm{p}}, \omega, n, \xi, v_{\mathrm{s}}\right)$ and three fundamental units (Mass, Length, Time) [7]. Note that the opening, in units of length, of the gap between soil and pile cap (Fig. 1) is not defined, as re-establishment of contact during dynamic response is not considered.

\section{Numerical model}

The parametric analysis is performed using a previously developed three-dimensional elastodynamic BEM-FEM coupling scheme [6]. The direct boundary element method (BEM) [8] in the frequency domain is used to model the dynamic behaviour of the soil, which is assumed to be a linear, homogeneous, isotropic, viscoelastic, unbounded region with hysteretic damping. However, it is assumed that the piles can be studied as load lines, with certain stiffness, but acting within the soil as volume loads, in such a way that the soil remains continuous and the piles can be modeled as elastic EulerBernoulli beams via one dimensional finite elements. With such assumption, the integral equation of the homogeneous linear elastodynamic problem is written taking into account the term corresponding to the domain forces, which are usually considered to be zero. After discretizing the different surfaces of the geometry into nine-node quadrilateral quadratic boundary elements, and the piles into three-node one-dimensional finite elements, a collocation procedure is carried out in order to write a set of boundary element equations for each domain of the problem. A set of finite element equations is also built for every pile. Finally, a linear system of equations is obtained for each frequency by taking into account the boundary *This is the peer-reviewed version of the following article: Padrón, Mylonakis, Beskos, Importance of footing-soil separation on dynamic stiffness of piled embedded footings, Int $\mathrm{J}$ Numerical and Analytical Methods in Geomechanics 2009; 33:1439-1448, which has been published in final form at http://onlinelibrary.wiley.com/doi/10.1002/eqe.2330/full. This article may be used for non-commercial purposes in accordance with Wiley Terms and Conditions for Self-Archiving. 
conditions and imposing equilibrium and compatibility at the interfaces of the different coupled regions in the problem.

An example of the meshes used in this study is depicted in Fig. 2. It is worth noting here that the full-space fundamental solution has been used to compute the BEM equations, which is the reason why a small region of the free soil surface has to be discretized. Fig. 2 illustrates the boundary conditions applied to the model, in which fully bonded contact conditions are considered in the vertical interfaces between soil and footing, and soil and pile. The gap between soil and the underside of the footing is modelled by pertinent zero-traction boundary conditions on the horizontal interface. In the numerical analyses, a minimum of 1145 nodes and 255 elements, and a maximum of 3600 nodes and 830 elements, depending on the configuration, were used. For more information on the model, the interested reader is referred to [6]. Detailed presentations of general BEM techniques for elastodynamic problems are provided in [8] and [9].

\section{Importance of footing-soil separation on dynamic stiffness of piled embedded footings}

The impedance functions of the foundations, which relate the forces (and moments) applied and the displacements (and rotations) observed at the top of the footing, are complex functions of the form $K=k+\mathrm{i} a_{0} c$, where $k$ and $c$ are the frequencydependent dynamic stiffness and damping coefficients, and $i=\sqrt{ }-1$ [12]. In this formulation, $\mathrm{k}$ and $\mathrm{c}$ have the same units, the former denoting storage stiffness and the latter loss stiffness. The relation between complex impedance functions of piled embedded footings considering either a gap $\left(K^{\mathrm{G}}\right)$ or bonded contact conditions $\left(K^{\mathrm{B}}\right)$ between soil and footing underside is determined for different oscillation modes. Differences in modulus and phase of the impedance functions are presented in terms of the following real-valued parameters:

$$
\begin{aligned}
& \chi_{G} \equiv \frac{\bmod \left(K^{\mathrm{B}}\right)-\bmod \left(K^{\mathrm{G}}\right)}{\bmod \left(K^{\mathrm{B}}\right)} \\
& \Theta_{G} \equiv \operatorname{phase}\left(K^{\mathrm{B}}\right)-\operatorname{phase}\left(K^{\mathrm{G}}\right)
\end{aligned}
$$

where

$$
\begin{aligned}
& \bmod (K)=\sqrt{k^{2}+\left(a_{o} c\right)^{2}} \\
& \text { phase }(K)=\arctan \left(\frac{-k}{a_{o} c}\right)+\frac{\pi}{2}
\end{aligned}
$$

Evidently, the limits $\chi_{\mathrm{G}} \rightarrow 0$ and $\Theta_{\mathrm{G}} \rightarrow 0$ indicate an insignificant effect of gapping on dynamic stiffness, whereas $\chi_{\mathrm{G}} \rightarrow \pm 1$ and $\Theta_{\mathrm{G}} \rightarrow \pm \pi$ suggest a dominant effect of gapping.

Results are shown in Figs. 3, 4 and 5 for vertical, horizontal and rocking oscillations, respectively. It can be observed that the differences between the

\footnotetext{
*This is the peer-reviewed version of the following article: Padrón, Mylonakis, Beskos, Importance of footing-soil separation on dynamic stiffness of piled embedded footings, Int J Numerical and Analytical Methods in Geomechanics 2009; 33:1439-1448, which has been published in final form at http://onlinelibrary.wiley.com/doi/10.1002/eqe.2330/full. This article may be used for non-commercial purposes in accordance with Wiley Terms and Conditions for Self-Archiving.
} 
impedance functions for separated and bonded conditions are negligible for frequencies below those for which dynamic group effects start making the system stiffer. Hence, for closely spaced groups $(s / d=2)$, differences are almost zero for $a_{0}<$ 1. For larger pile spacings $(s / d=5)$, they become significant for $a_{0}>0.25$ in the vertical mode and for $a_{\mathrm{o}}>0.4$ in the horizontal and rocking modes. These threshold frequencies are in accord with those reported for dynamic group effects [10, 11]. Interestingly, these differences can be either positive or negative that is, the gap may decrease or increase the stiffness of the system due to wave interference depending on excitation frequency. The effect of separation is, naturally, more noticeable in the vertical mode and may decrease the stiffness of the system by $50 \%$ beyond $a_{\mathrm{o}}=0.5$. On the other hand, the change in stiffness in the lateral mode is smaller and does not exceed a mere $20 \%$.

An important issue relates to the redistribution of the relative contributions of piles and footing to overall stiffness, so that the difference between $K^{\mathrm{G}}$ and $K^{\mathrm{B}}$ is negligible at low frequencies. To investigate this, Fig. 6 shows a comparison between the impedance functions of simple embedded footings for which the piles have been removed (termed here "un-piled" footing), and the contribution of the footing to the stiffness of a ground-contacting piled footing for different embedment ratios, $E_{\mathrm{p}} / E_{\mathrm{s}}=$ 1000 and $s / d=5$. As expected, the stiffness of the un-piled footing is higher than its contribution to the overall stiffness in a piled foundation. On the other hand, Fig. 7 compares the impedance functions of a $2 \times 2$ pile group with a cap at ground surface level and the contribution of the pile group to the stiffness of a ground-contacting piled footing for the same embedment ratios $\left(E_{\mathrm{p}} / E_{\mathrm{s}}=1000\right.$ and $\left.s / d=5\right)$. In this case, the static stiffness of the ground-raised cap pile group is twice the contribution of the pile group to the overall stiffness of a piled ground-contacting foundation. Then, when a gap develops at the underside of a piled footing, the loss of stiffness of the footing is counterbalanced by the increase in stiffness of the pile group.

Finally, Fig. 7 shows that the contribution of the pile group to the overall stiffness of the piled footing is independent of embedment ratio. This suggests that the impedance functions of a pile group are governed by the boundary conditions at the surface immediately above the cap, which should be taken into account when estimating impedances of piled footings by superposition.

\section{Conclusions}

Numerical parametric analyses were carried out to investigate the influence, on dynamic stiffness and damping, of loss of contact between soil and the underside of an embedded footing reinforced with piles, due to soil consolidation, erosion or scour effects. The study has been performed in the frequency domain using a rigorous linear three-dimensional BEM-FEM formulation considering piles as Euler-Bernoulli beams and soil as a homogeneous, isotropic, viscoelastic, unbounded material with frequency independent damping. Fully bonded contact conditions were assumed in the vertical soil-footing and soil-pile interfaces.

It was demonstrated that under the above assumptions:

(1) The influence of separation is negligible for frequencies below those for which dynamic group effects start becoming apparent.

\footnotetext{
*This is the peer-reviewed version of the following article: Padrón, Mylonakis, Beskos, Importance of footing-soil separation on dynamic stiffness of piled embedded footings, Int J Numerical and Analytical Methods in Geomechanics 2009; 33:1439-1448, which has been published in final form at http://onlinelibrary.wiley.com/doi/10.1002/eqe.2330/full. This article may be used for non-commercial purposes in accordance with Wiley Terms and Conditions for Self-Archiving.
} 
(2) The effect of separation is more noticeable in the vertical mode and may decrease the stiffness of the system by $50 \%$ beyond $a_{\mathrm{o}}=0.5$. On the other hand, the change in stiffness is minimized in the lateral mode and does not exceed $20 \%$.

(3) The overall stiffness of the foundation when no separation exists is not necessarily higher than that corresponding to the system after soil consolidation/erosion/scour. The relationship between the dynamic stiffness in both cases depends on the constructive and destructive interference of the waves generated at the pile-soil and the footing-soil interfaces and, therefore, it is frequency-dependent.

(4) A counterbalance between footing and pile group stiffness contributions was found to exist under loss of soil-pile cap contact.

(5) The contribution of the pile group to the overall stiffness of the system is independent of embedment, but depends on the ground-cap contact condition, i.e., changes between ground-raised and ground-contacting caps. This property can be used to simplify the models when estimating the dynamic stiffness functions of piled footings by superposition approaches.

\section{Acknowledgments}

This work was partially supported by the Ministry of Education and Science of Spain through research project BIA2007-67612-C02-01, co-financed by the European Fund of Regional Development. L.A. Padrón is recipient of the FPU research fellowship AP-2004-4858 also from the Ministry of Education and Science of Spain. The second Author is indebted to Professor Jonathan P. Stewart, University of California, Los Angeles, for many fruitful discussions on the topic. The authors would like to thank the anonymous reviewers for their valuable comments and suggestions.

\section{References}

1. Akinmusuru JO. Interaction of piles and cap in piled footings. $J$ Geotech Eng Div ASCE 1980 ; 106(11): 1263-68.

2. Chow YK and Teh CI. Pile-cap-pile-group interaction in nonhomogeneous soil. J Geotech Eng ASCE 1991; 117(11): 1655-68.

3. Butterfield $\mathrm{R}$ and Banerjee PK. The problem of pile group-pile cap interaction, Geotechnique 1971; 21(2): 135-42.

4. Poulos H. Piled raft foundations: Design and applications, Geotechnique, 2001; 51(2): 95-113.

5. Small JC and Poulos HG. Non-linear analysis of piled raft foundations; Geotechnical Special Publication ASCE, 2007, 158, ASCE

6. Padrón LA, Aznárez JJ and Maeso O. BEM-FEM coupling model for the dynamic analysis of piles and pile groups. Eng Anal Boundary Elem 2007 ; 31(6) : 473-84.

\footnotetext{
*This is the peer-reviewed version of the following article: Padrón, Mylonakis, Beskos, Importance of footing-soil separation on dynamic stiffness of piled embedded footings, Int J Numerical and Analytical Methods in Geomechanics 2009; 33:1439-1448, which has been published in final form at http://onlinelibrary.wiley.com/doi/10.1002/eqe.2330/full. This article may be used for non-commercial purposes in accordance with Wiley Terms and Conditions for Self-Archiving.
} 
7. Buckingham E. On physically similar systems: illustration of the use of dimensional equations, Phys. Rev. 1914; 4: 345-376.

8. Domínguez J. Boundary elements in dynamics, Southampton, New York: Computational Mechanics Publications \& Elsevier Applied Science, 1993

9. Beskos DE. Boundary element methods in dynamic analysis: Part II (19861996), Appl. Mech. Rev. 1997, ASME, 50, 149-197

10. Mylonakis G. Contributions to static and seismic analysis of piles and pilesupported bridge piers. Ph.D. dissertation, State University of New York at Buffalo, 1995.

11. Kaynia AM and Kausel E. Dynamic stiffness and seismic response of pile groups. Research Report R82-03, Massachusetts Inst. of Technology, 1982.

12. Mylonakis G, Nikolaou S and Gazetas G. Footings under Dynamics Loads: Analysis and Design Issues with Emphasis on Bridge Foundations, Soil Dynamics and Earthquake Engineering 2006; 26(9): 824-853.

\footnotetext{
*This is the peer-reviewed version of the following article: Padrón, Mylonakis, Beskos, Importance of footing-soil separation on dynamic stiffness of piled embedded footings, Int $\mathrm{J}$ Numerical and Analytical Methods in Geomechanics 2009; 33:1439-1448, which has been published in final form at http://onlinelibrary.wiley.com/doi/10.1002/eqe.2330/full. This article may be used for non-commercial purposes in accordance with Wiley Terms and Conditions for Self-Archiving.
} 


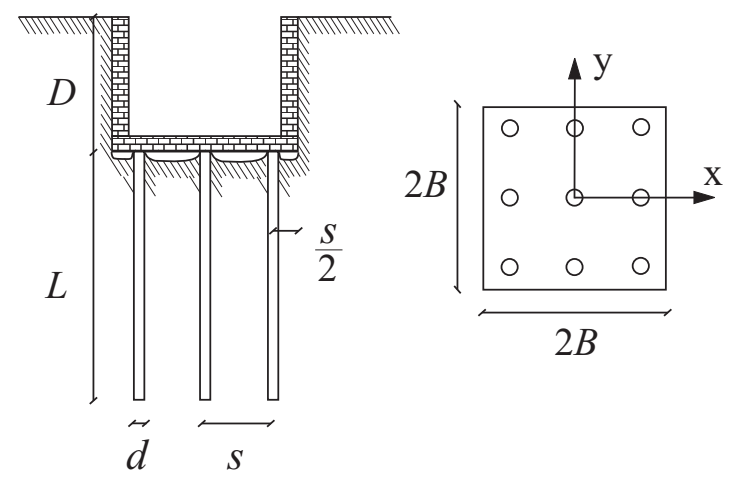

Figure 1: Geometry of an embedded footing on piles with footing-soil separation at the base

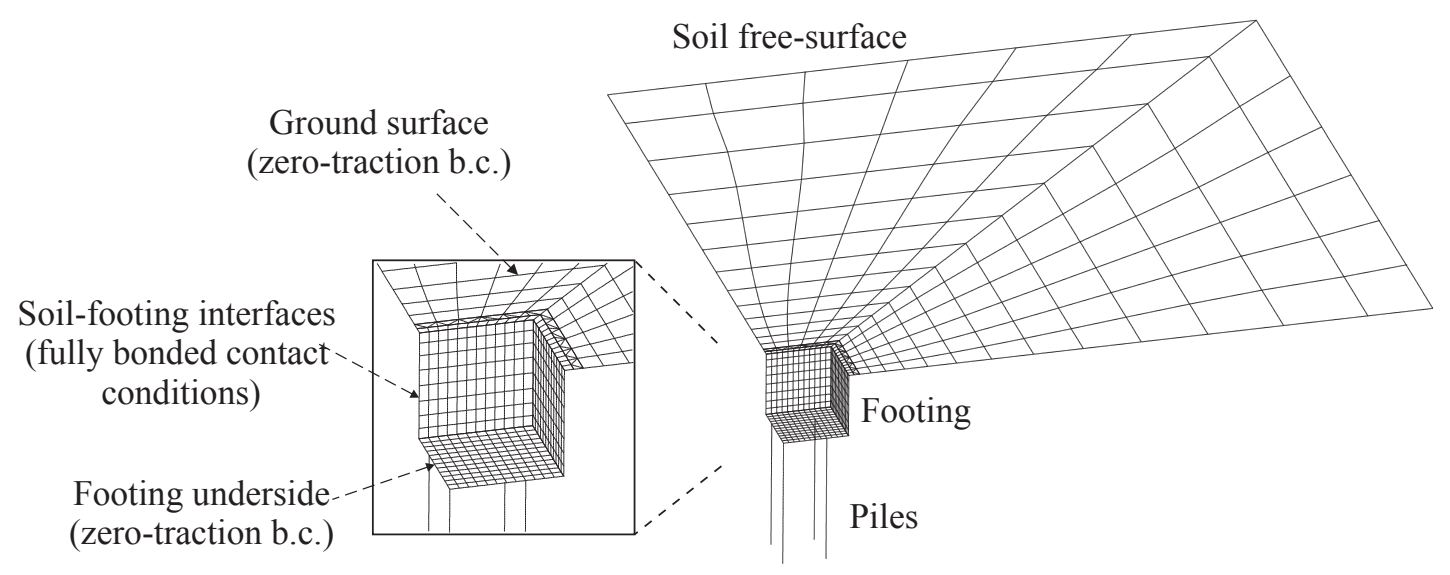

Figure 2: Discretization of one-quarter of an embedded footing on a $3 \times 3$ pile group 

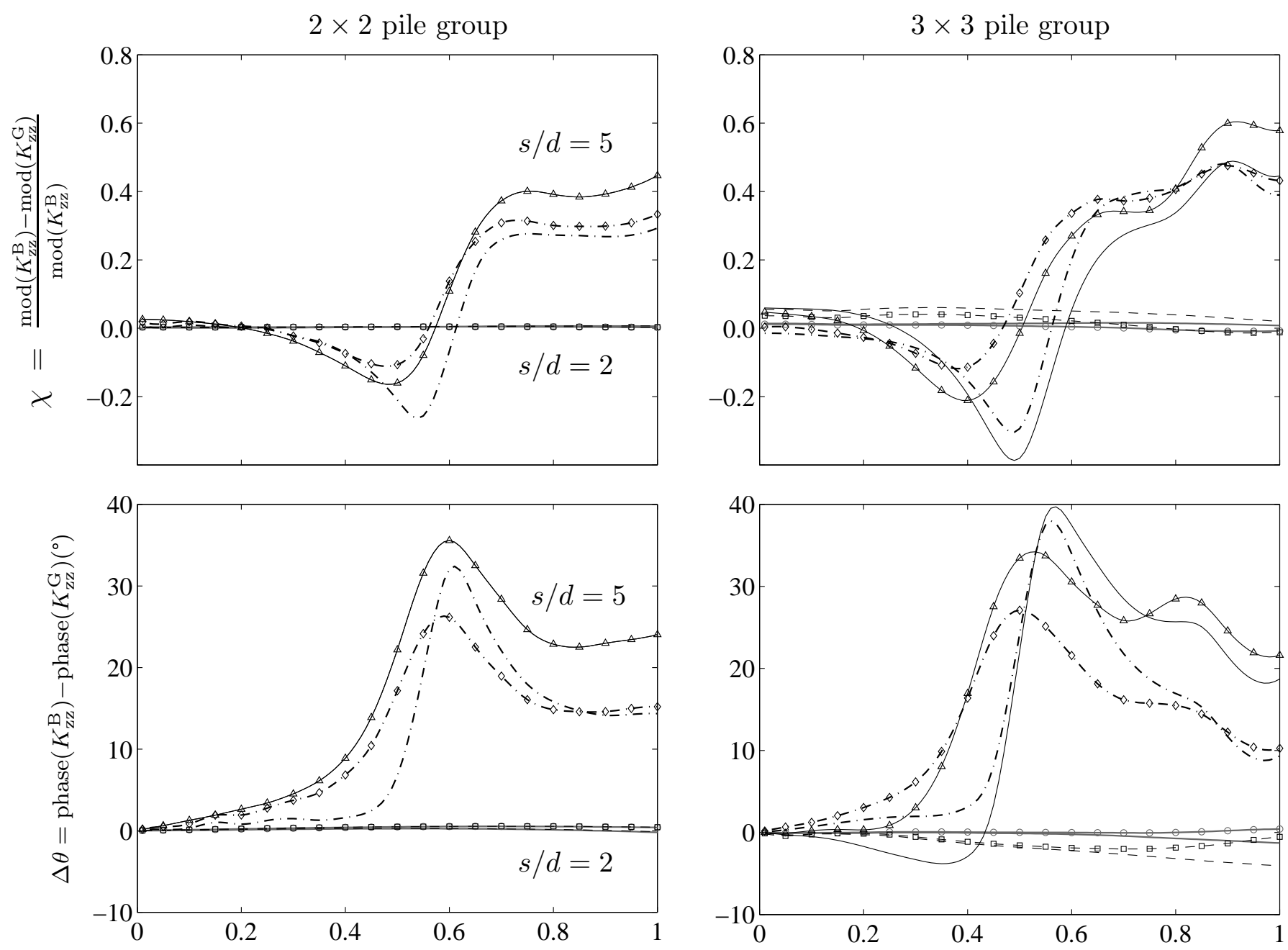

$$
a_{o}=\frac{\omega d}{c_{s}}
$$

\begin{tabular}{|c|c|}
\hline $\begin{aligned}-s / d & =2, D / B=1, E_{p} / E_{s}=1000 \\
--s / d=2, D / B & =1, E_{p} / E_{s}=100 \\
---s / d=2, D / B & =2, E_{p} / E_{s}=1000 \\
-\neg--s / d=2, D / B & =2, E_{p} / E_{s}=100\end{aligned}$ & 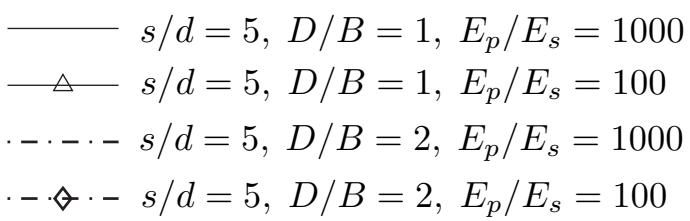 \\
\hline
\end{tabular}

Figure 3: Comparison between modulus and phase of vertical dynamic impedances of embedded footings on piles considering a gap $K_{\mathrm{zz}}^{\mathrm{G}}$ or bonded contact conditions $K_{\mathrm{zz}}^{\mathrm{B}}$ between soil and footing underside. 

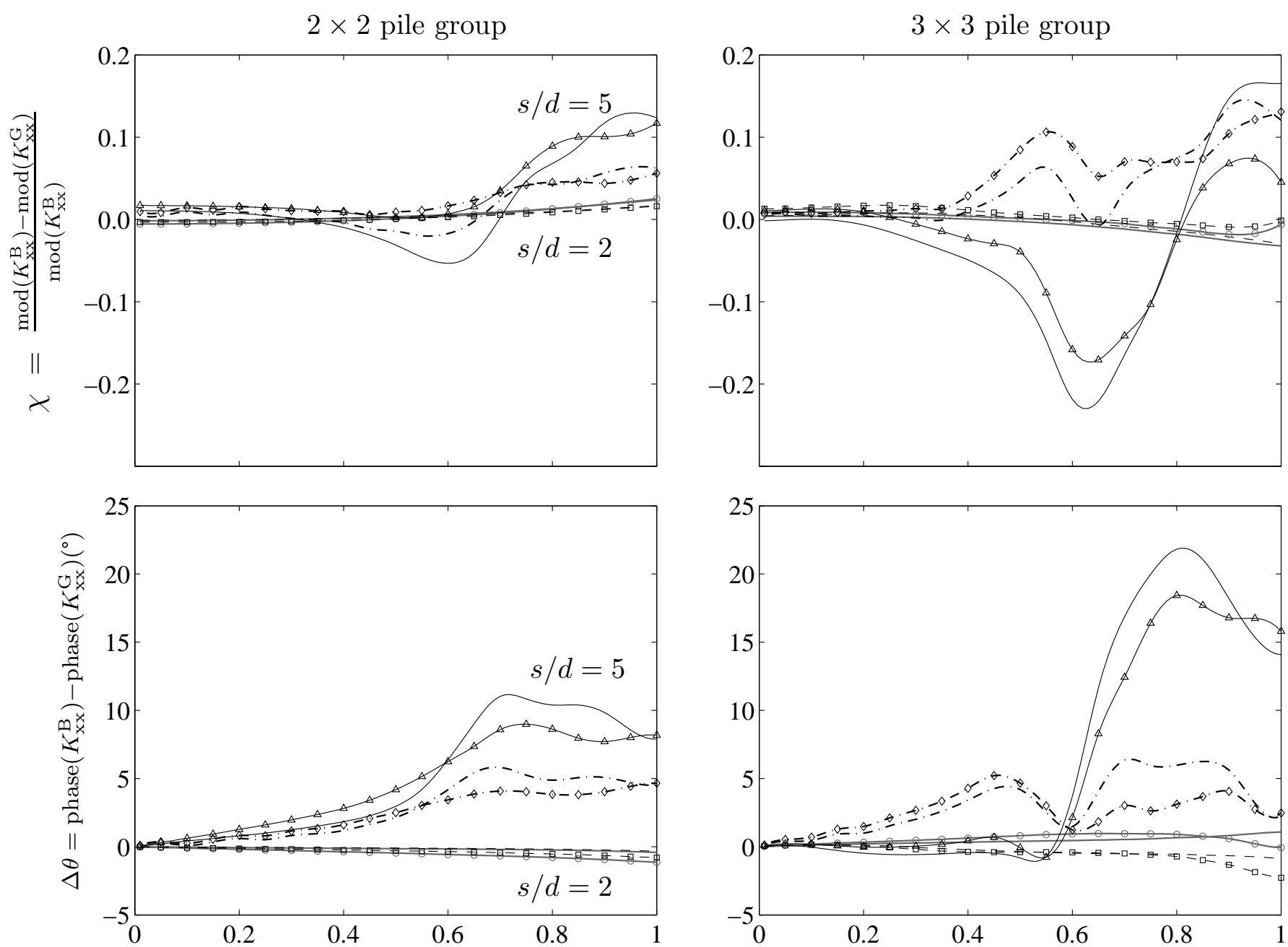

$$
a_{o}=\frac{\omega d}{c_{s}}
$$

\begin{tabular}{|c|c|}
\hline $\begin{aligned}-s / d & =2, D / B=1, E_{p} / E_{s}=1000 \\
-s / d & =2, D / B=1, E_{p} / E_{s}=100 \\
---s / d=2, D / B & =2, E_{p} / E_{s}=1000 \\
-\neg--s / d=2, D / B & =2, E_{p} / E_{s}=100\end{aligned}$ & 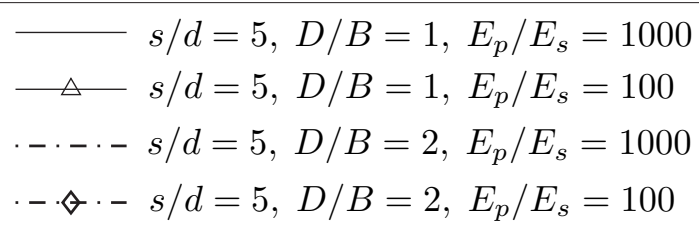 \\
\hline
\end{tabular}

Figure 4: Comparison between modulus and phase of horizontal dynamic impedances of embedded footings on piles considering a gap $K_{\mathrm{xx}}^{\mathrm{G}}$ or bonded contact conditions $K_{\mathrm{xx}}^{\mathrm{B}}$ between soil and footing underside. 

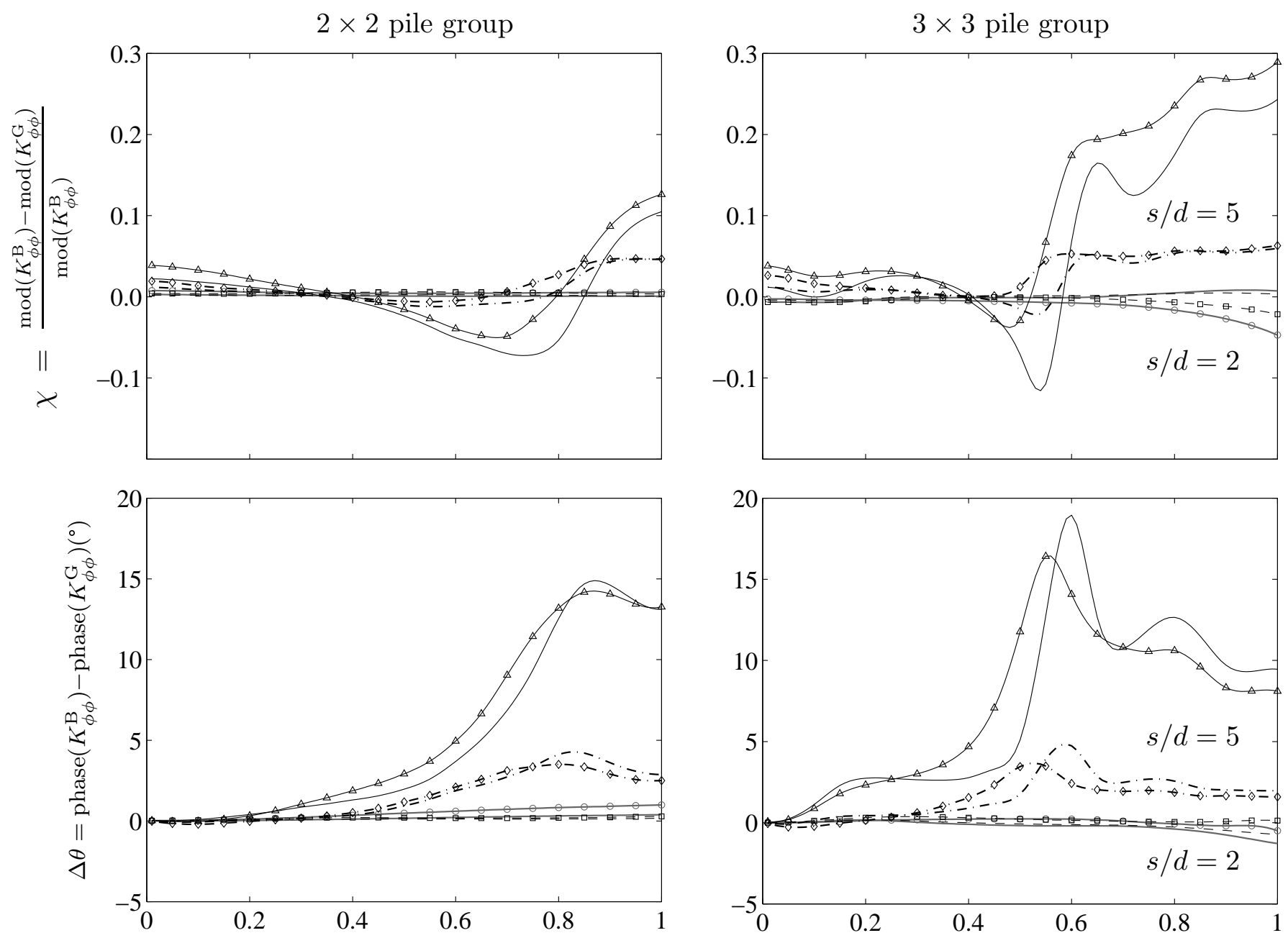

$$
a_{o}=\frac{\omega d}{c_{s}}
$$

\begin{tabular}{|c|c|}
\hline $\begin{aligned}-s / d & =2, D / B=1, E_{p} / E_{s}=1000 \\
-s / d & =2, D / B=1, E_{p} / E_{s}=100 \\
---s / d=2, D / B & =2, E_{p} / E_{s}=1000 \\
-\neg--s / d & =2, D / B=2, E_{p} / E_{s}=100\end{aligned}$ & 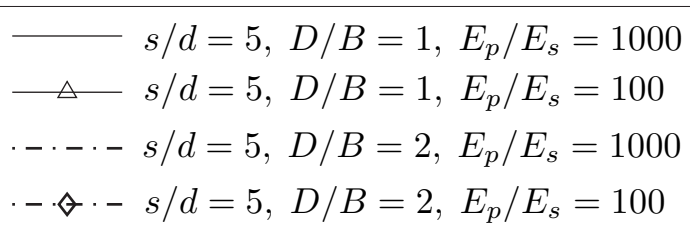 \\
\hline
\end{tabular}

Figure 5: Comparison between modulus and phase of rocking dynamic impedances of embedded footings on piles considering a gap $K_{\phi \phi}^{\mathrm{G}}$ or bonded contact conditions $K_{\phi \phi}^{\mathrm{B}}$ between soil footing underside. 


\begin{tabular}{|lll|}
$\mathbf{D}=\mathbf{0} \quad$ : piled footing $\cdots$ & unpiled footing $\diamond$ \\
$\mathbf{D}=\mathbf{B}$ : piled footing --- & unpiled footing $\circ$ \\
$\mathbf{D}=\mathbf{2 B}$ : piled footing & - & unpiled footing $\Delta$ \\
\hline
\end{tabular}
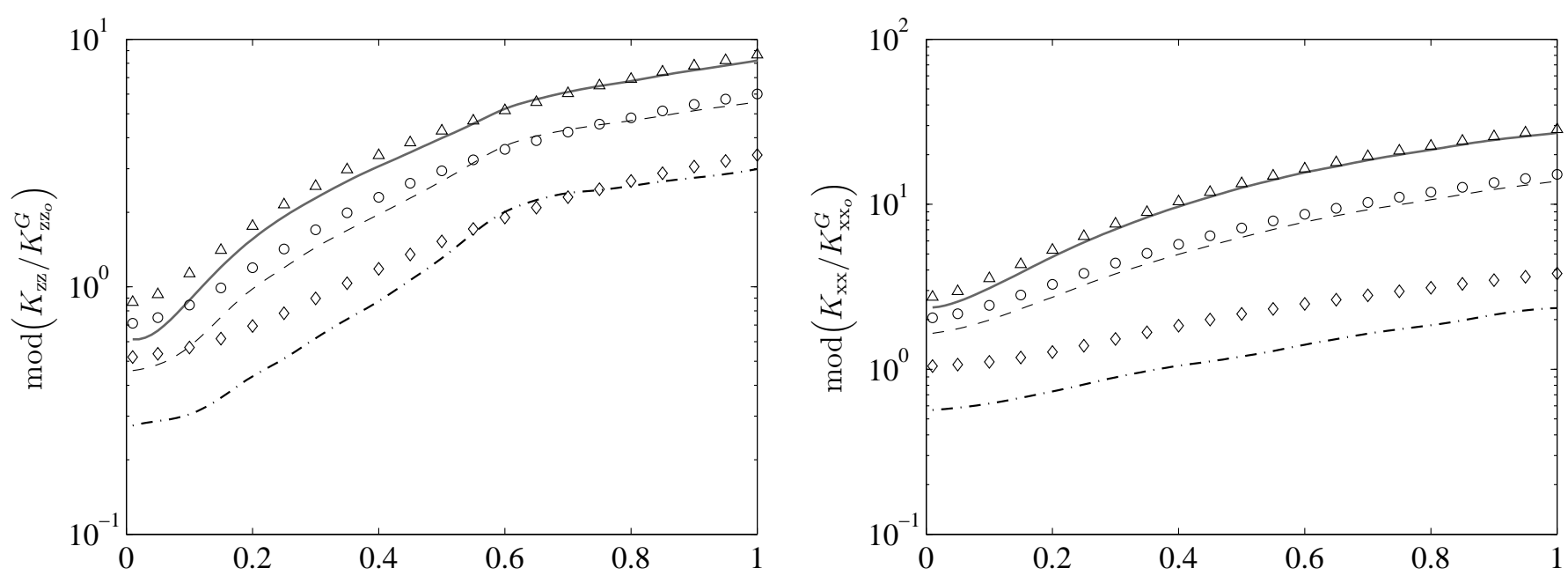

$$
a_{o}=\frac{\omega d}{c_{s}}
$$

Figure 6: Comparison between the dynamic impedances of unpiled footings and the contribution of the footing to the dynamic impedance function of a ground-contacting piled footing for different embedments. $E_{p} / E_{s}=1000, s / d=5$. 


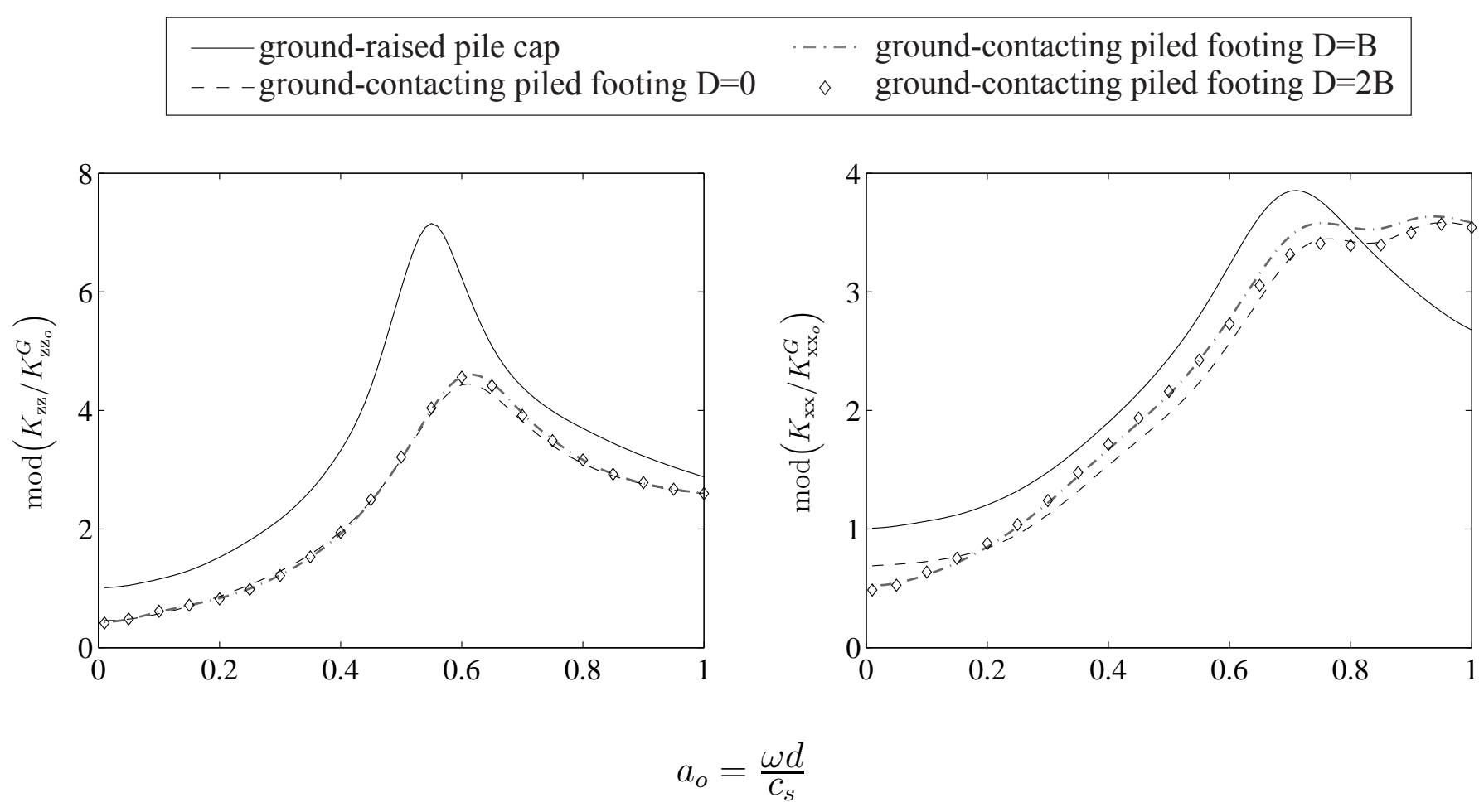

Figure 7: Comparison between the dynamic impedances of a ground-raised-cap $2 \times 2$ pile group and the contribution of the pile group to the dynamic impedance function of a ground-contacting piled footing for different embedments. $E_{p} / E_{s}=1000, s / d=5$. 